\title{
Evaluation of Psychological Factors in Alopecia Areata
}

\author{
Nazli Dizen Namdar (Corresponding author) \\ School of Medicine, Department of Dermatology, Kutahya Health Sciences University, \\ 43100, Kutahya Turkey \\ E-mail: nazli.dizennamdar@ksbu.edu.tr \\ Yasemin Kurtoglu \\ School of Medicine, Department of Family Medicine, Kutahya Health Sciences University \\ 43100, Kutahya Turkey \\ E-mail: yasemin.kurtoglu@ksbu.edu.tr
}

\begin{abstract}
It is suggested that psychiatric disorders play a role in the pathogenesis of alopecia areata (AA), and the disease itself can lead to psychiatric disorders. The aim of this study is to evaluate the levels of depression, anxiety, and alexithymia in AA patients and to determine their relationship with the clinical features of the disease. The study included 73 AA patients and 73 healthy individuals. All participants were evaluated with the Beck depression scale, Beck anxiety scale and Toronto alexithymia scale. The severity of depression and anxiety symptoms of the patients were found to be significantly higher than the controls ( $p=, 001$ and $p=, 003$, respectively). It was observed that there was no significant difference between the two groups in terms of the level of alexithymic properties $(p=, 059)$. In AA patients, there was no statistically significant relationship between psychiatric symptoms and the patient's age, duration of the disease and severity of the disease $(p>0.05)$. A significant relationship was observed between the level of depression and the sex of the patient $(r=0.43 ; p=0.042)$. Consequently, because of the symptoms of depression and anxiety in AA patients, patients should not only be handled in terms of skin lesions but also should be evaluated psychologically and should be referred to the psychiatry outpatient clinic when necessary. Thus, we think that the success of treatment can be increased.
\end{abstract}

Keywords: Alopecia areata, Depression, Anxiety, Alexithymia.

\section{Special Issue of Health Sciences}

DOI: $10.7176 / \mathrm{JSTR} / 6-03-16$

\section{Alopesi Areatada Psikolojik Faktörlerin Değerlendirilmesi}

\section{Özet}

Alopesi areata (AA) patogenezinde psikiyatrik bozuklukların rolü olduğu ve hastalığın kendisinin de psikiyatrik bozukluklara yol açabileceği ileri sürülmektedir. Bu çalışmanın amacı AA hastalarında depresyon, anksiyete ve aleksitimi düzeylerinin değerlendirilmesi ve hastalığın klinik özellikleri ile ilişkisinin saptanmasıdır. Çalışmaya 73 AA tanılı hasta ile 73 sağlıklı kişiden oluşan kontrol grubu alındı. Tüm katılımcılar; Beck depresyon ölçeği, Beck anksiyete ölçeği ve Toronto aleksitimi ölçeği ile değerlendirildiler. Hastaların depresyon ve anksiyete belirtilerinin şiddeti kontrollerden anlamlı olarak daha yüksek saptandı (sırasıyla $p=, 001$ ve $p=, 003$ ). Aleksitimik özelliklerin düzeyi açısından iki grup arasında anlamlı farklılık bulunmadığı gözlendi $(\mathrm{p}=, 059)$. AA hastalarında; psikiyatrik belirtiler ile hastanın yaşı, hastalığın süresi ve hastalığın şiddeti arasında istatistiksel olarak anlamlı bir ilişki saptanmadı $(\mathrm{p}>0,05)$. Depresyon düzeyi ile hastanın cinsiyeti arasında anlamlı bir ilişki gözlendi $(\mathrm{r}=0,43$; $\mathrm{p}=0,042)$. Sonuç olarak AA hastalarında depresyon ve anksiyete bulgularına rastlanması nedeniyle, hastalar sadece deri lezyonları açısından ele alınmamalı aynı zamanda psikolojik olarak da 
değerlendirilmeli ve gerekli durumlarda psikiyatri polikliniğine yönlendirilmelidir. Böylece tedavi başarısının artırılabileceğini düşünmekteyiz.

Anahtar kelimeler: Alopesi areata, Depresyon, Anksiyete, Aleksitimi

\section{Giriş}

Alopesi areata (AA), sıklıkla saçlı derideki kılların ani dökülmesiyle karakterize sık görülen bir hastalıktır (Ar1 ve ark. 2011, Dizen-Namdar ve ark. 2019). AA'nın etyopatogenezi halen bilinmemekle beraber, genetik yatkınlık zemininde çevresel tetikleyici faktörlerin etkisiyle gelişen, organ spesifik otoimmün kıl folikülü hastalığı olduğu düşünülmektedir (Ar1 ve ark. 2011, Dizen-Namdar ve ark. 2019, Şahin ve ark. 2018). AA'da lezyonlar sıklıkla saçlı deride yerleşmektedir. Hastalık yaşamı tehdit edici olmasa da özellikle derinin görünür bölgelerdeki lezyonlar, ciddi kozmetik problemlere neden olmaktadır (Dizen-Namdar ve ark. 2019, Rajoo ve ark. 2019).

AA ve psikiyatrik bozukluklar arasında karşılıklı bir ilişki vardır. Psikiyatrik bozukluklar AA oluşumunu tetikleyebilir, aynı zamanda hastalığın olumsuz etkileriyle yeni psikiyatrik bozukluklar gelişebilir veya var olanları şiddetlenebilir (Mulinari-Brenner 2018). AA eşlik edebilen psikiyatrik hastalıkların veya psikiyatrik bozuklukların normal popülasyona göre yüksek olduğu bildirilmektedir. Anksiyete; kayg1, endişe, gerginlik, huzursuzluk, bunaltı hali olarak ifade edilir. Anksiyete bozuklukları kişinin hayat kalitesini ve toplumun sağlığını da ciddi boyutlarda etkileyen psikiyatrik bozukluktur (Aydoğan ve ark. 2012). AA'lı hastalarda en sik görülen psikiyatrik rahatsızlıklar anksiyete ve depresyon olduğu saptanmıştır (Ar1 ve ark. 2011, Rajoo ve ark. 2019, Mulinari-Brenner 2018, Ghajarzadeh ve ark. 2011). Aleksitimi bireyin kendisinin ve başka kişilerin duygularını fark etme, tanıma, ayırt etme ve ifade etmede güçlük olarak tanımlanmıştır (Sifneos 1988). Çalışmalarda aleksitiminin sadece psikosomatik hastalıklarda değil, çeşitli tıbbi ve psikiyatrik hastalıklarda ve genel popülasyonda da izlenildiği bildirilmiştir (Şaşığlu ve ark. 2013). Son yıllarda AA ile aleksitimi arasında ilişki olduğu saptanmıştır (Yazıcı ve ark. 2006, Picardi ve ark. 2003, Poot 2004).

$\mathrm{Bu}$ çalışmada AA hastalarında anksiyete ve depresyon düzeyleri ile aleksitimik özelliklerin değerlendirilmesi ve hastalık üzerine etkilerinin incelenmesi amaçlamıştır.

\section{Materyal ve Metod}

\section{1 Çalışma grubu}

Çalışmamıza, Kütahya Sağlık Bilimleri Üniversitesi Tıp Fakültesi Evliya Çelebi Eğitim ve Araştırma Hastanesi Dermatoloji polikliniğinde tanısı konulan, AA'lı 73 hasta ile aile hekimliği polikliniğine rutin kontroller için başvuran hasta ve hasta yakınlarından oluşan 73 sağlıklı kişi dahil edildi. Çalışmaya katılmayı kabul eden tüm kişilerin okur-yazar olması ve 18-65 yaş arasında olması şartı arandı. Daha önce psikiyatrik tanı ve tedavi alanlar, nörolojik hastalığı olanlar çalışmadan dışlandı.

AA'lı hastaların tanısı dermatolojik muayene ile konuldu. Hastalığın şiddeti, Olsen ve arkadaşları tarafından bildirilen tüm alopesik alanların saçlı deride kapladığı toplam alanın yüzdesinin belirlenmesine göre hesaplandı: S0: saç kaybı yok; S1: saç kayb1<\%25; S2: saç kayb1 \%26-50; S3: saç kaybı \%51-75; S4: saç kaybı \%76-99; S5: saç kayb1 \%100 (Olsen ve ark. 2004). Hastalarımızın tümünün $\mathrm{S} 1$ ve S2 gruplarında yer aldı̆̆ 1 görüldü.

Tüm katılımcılara ise "Beck Depresyon Ölçeği”" (BDÖ), "Beck Anksiyete Ölçeği”" (BAÖ), 20 soruluk "Toronto Aleksitimi Ölçeği”" (TAÖ-20) doldurtuldu. Çalışmamız için etik kurul onayı alındı.

\subsubsection{Beck Depresyon Ölçeği (BDÖ)}

Depresif belirti ve tutumun saptanması için uygulanan değerlendirme ölçeğidir. 21 maddeden oluşan ölçekte, her madde 0-3 arasında değişen puan alır. Toplam puanın yüksekliği, depresyon düzeyinin yüksekliğini göstermektedir (Beck ve ark. 1961). Ölçeğin, ülkemizde geçerlik ve güvenirlik çalışması yapılmıştır (Hisli 1988).

\subsubsection{Beck Anksiyete Ölçeği (BAÖ)}

Anksiyete düzeyini saptamak için kullanılan, kendini değerlendirme ölçeğidir. 21 maddeden oluşan ölçekte, her madde 0-3 arasında değişen puan almaktadır. Toplam puanın yüksek olması, anksiyete seviyesinin yüksekliğini göstermektedir (Beck ve ark. 1988). Ülkemizde geçerlilik ve güvenirlik çalışması yapılmıştır (Ulusoy ve ark. 1988). 


\subsubsection{Toronto Aleksitimi Ölçeği-20 (TAÖ-20)}

Aleksitimiyi değerlendiren ölçek, her maddesi 1-5 arası puan alan toplam 20 maddeden oluşmaktadır. Alınan yüksek puanlar yüksek aleksitimik düzeyi göstermektedir (Bagby ve ark. 1994). Türkiye'de geçerlik ve güvenirlilik çalı̧̧ması yapılmıştır (Güleç ve ark. 2009). Bu ölçekte, duygularını tanımada güçlük, duygularını söze dökmede güçlük ve dışa dönük düşünme alt grupları vardır. Ölçeğin Türkçe sürümünün kesme puanı 59 olarak belirtilmiştir, 59 ve üzerinde puan alan bireyler aleksitimik olarak değerlendirilmiştir (Güleç ve ark. 2010, Taycan ve ark. 2017). Çalışmamızda da genel aleksitimi puanı kullanılmış, kesme puanına göre değerlendirme yapılmıştır.

\section{2 İstatistik Değerlendirmesi}

Verilerin değerlendirmesinde; normal dağılıma uygunluğu değerlendirilmek için Kolmogorov-Smirnov testi uygulandı. Değerlendirmede kesikli değişkenlerin karşılaştırılmasında ki kare testi, sürekli değişkenlerin analizinde ise bağımsız gruplarda $t$ testi kullanıldı. Sürekli değişkenler arasındaki korelasyonun incelenmesinde Pearson korelasyon analizi yapıldı. $\mathrm{p} \leq 0.05$ istatiksel olarak anlamlı kabul edildi.

\section{Bulgular}

Çalışma grubumuz toplam 146 kişi olup, \%50'si kontrol grubu \%50'si AA tanılı hastalardı ve \%52'si erkek, \%48'i kadın idi. AA'lı hastalarımızın yaş ortalaması $28,58 \pm 8,56$ iken, kontrol grubumuzun 35,88 $\pm 13,61$ idi. Çalışma grubumuzda, hasta ve kontrol grubumuz cinsiyet açısından benzer olup, istatistiksel açıdan anlamlı bir fark yokken ( $\mathrm{p}>0,05)$, yaş açısından ise istatiksel olarak anlamlı bir fark vardı ( $\mathrm{p}:, 001)$ (Tablo 1).

Hasta grubunda BDÖ ve BAÖ puanları kontrol grubundan daha yüksek bulunurken, TAÖ puanları açısından her iki grup arasında istatistiksel açıdan fark saptanmadı (Tablo 2). Aleksitimi kesme puanına göre AA hastalarının \%23,3'ünde kontrol grubunun ise \%12,3'ünde aleksitimik olarak saptandı. İki grup karşılaştırıldığında, aleksitimik durum açısından istatistiksel olarak anlamlı bir fark saptanmadı (p: ,084) (Tablo 2). 0.95 güven düzeyinde Pearson korelasyon katsayısı ve ki-kare $\left(\chi^{2}\right)$ testi ile incelendiğinde AA hastalarında; BDÖ, BAÖ ve TAÖ puanları ile hastanın yaşı, hastalığın süresi, hastalı̆̆ın şiddeti arasında istatistiksel açıdan anlamlı bir ilişki yoktu ( $>00,05)$. BAÖ, TAÖ puanları ile hastanın cinsiyeti arasında istatistiksel olarak anlamlı bir ilişki saptanmadı ( $>0,05)$, ancak BDÖ puanı ile hastanın cinsiyeti arasında anlamlı bir ilişki vardı $(r=0,43 ; \mathrm{p}=0,042)$.

Table 1. Hasta ve kontrol grubunun yaş ve cinsiyet dağılımı

\begin{tabular}{|c|c|c|c|c|}
\hline & Hasta(N:73) & Kontrol(N:73) & $\mathrm{t}$ & $\mathrm{p}$ \\
\hline $\begin{array}{c}\text { Yaş } \\
\text { Ort } \pm \text { SS }\end{array}$ & $28,58 \pm 8,56$ & $35,88 \pm 13,61$ & 3,87 & ,000 \\
\hline & $\mathrm{n}(\%)$ & $\mathrm{n}(\%)$ & $\chi^{2}$ & $\mathrm{p}$ \\
\hline $\begin{array}{l}\text { Cinsiyet } \\
\text { Erkek } \\
\text { Kadın }\end{array}$ & $\begin{array}{l}39(53,4) \\
34(46,6)\end{array}$ & $\begin{array}{l}37(50,7) \\
36(49,3)\end{array}$ & 0,11 & 0,74 \\
\hline
\end{tabular}

t: Student's t test; $\chi^{2}$ : Chi square test 
Tablo 2. Hasta ve kontrol grubunun beck depresyon, beck anksiyete, Toronto aleksitimi ölçeği puanlarının ve aleksitimi durumunun karşılaştırılması

\begin{tabular}{|c|c|c|c|c|}
\hline & Hasta & Kontrol & $t$ & $\mathrm{p}$ \\
\hline $\begin{array}{c}\text { Beck depresyon } \\
\text { Ort } \pm \text { SS }\end{array}$ & $12,60 \pm 9,85$ & $8,00 \pm 6,69$ & 3,30 & ,001 \\
\hline $\begin{array}{c}\text { Beck Anksiyete } \\
\text { Ort } \pm \text { SS }\end{array}$ & $13,07 \pm 13,36$ & $7,70 \pm 7,28$ & 3,01 & ,003 \\
\hline $\begin{array}{c}\text { TAÖ } \\
\text { Ort } \pm \text { SS }\end{array}$ & $49,93 \pm 13,08$ & $46,32 \pm 9,57$ & 1,90 & ,059 \\
\hline & $\mathrm{n}(\%)$ & $\mathrm{n}(\%)$ & $\chi^{2}$ & $\mathrm{p}$ \\
\hline $\begin{array}{c}\text { *Aleksetimi } \\
\text { durumu } \\
\text { Yok } \\
\text { Var }\end{array}$ & $\begin{array}{l}56(76,71) \\
17(23,29)\end{array}$ & $\begin{array}{c}64(87,67) \\
9(12,33)\end{array}$ & 2,99 & ,084 \\
\hline
\end{tabular}

t: Student's t test; $\chi^{2}$ : Chi square test, *Satır yüzdesi alınmıştır.

\section{Tartışma}

AA’nın günümüzde psikosomatik hastalıklar grubu içinde olduğu kabul edildiğinden dolayı araştırmacılar tarafından psikolojik faktörlerle ilişkisi üzerine birçok çalışma yapılmıştır, ancak sonuçlar çelişkilidir. Depresyon ve anksiyete AA'da en fazla saptanan psikiyatrik bozukluklardır (Arı ve ark. 2011, Rajoo ve ark. 2019, Mulinari-Brenner 2018). Colon ve arkadaşları (Colon ve ark. 1991), sıklıkla major depresyon ve yaygın anksiyete bozukluğu başta olmak üzere AA'lıların \%74'ünün yaşamları boyunca en az bir defa psikiyatrik hastalık tanısı konulduğunu saptamışlardır. Ülkemizde yapılan bir çalışmada (Çelik ve ark. 2010) olduğu gibi çalışmamızda AA'lı hastalarımızda depresyon ve anksiyete puanlarını kontrollere göre istatistiksel olarak anlamlı şekilde daha yüksek saptadık. Yine ülkemizde sadece BDÖ’ nün değerlendirildiği bir çalışmada AA'lı hastalarda anlamlı şekilde yüksek saptanmış (Şahin ve ark. 2018). Farklı olarak bazı çalışmalarda hasta ve kontroller arasında depresyon ve anksiyete seviyeleri arasında fark olmadığını bildirmişlerdir (Yazıcı ve ark. 2006, Güleç ve ark. 2002, Çalıkoğlu ve ark. 2000). Başka bir çalışmada ise AA'lı hasta grubunda kontrollere göre BDÖ puanını yüksek olarak saptanırken, BAÖ puanında anlamlı farklılık bulunmadığı saptanmıştır (Yaylı ve ark. 2012).

Literatürde psikosomatik hastalıklarda aleksitiminin daha sık gözlendiği ve aleksitiminin immün fonksiyonda bozulmalara sebep olabileceği bildirilmektedir (Yazıcı ve ark. 2006, Picardi ve ark. 2003). AA hastalarında aleksitimi yaygınlığı genel popülasyona göre daha yüksek olduğu saptanmıştır (Ghanizadeh ve ark. 2014). Çalışmamızda AA hastaların \% 23,3'ünde aleksitimi saptadık, ancak kontrol grubuyla karşılaştırdı̆̆ımız anlamlı bir fark saptamadık. Aynı şekilde toplam TAÖ puanı ile de hasta ve kontrol arasında anlamlı bir fark saptamadık. Benzer şekilde (Doruk ve ark. 2009), sadece erkek hastalardan oluşan çalışma gruplarında AA'lı hastalarda aleksitimi açısından anlamlı fark olmadığını bildirmişlerdir. (Arı ve ark. 2011) ise AA'lı hastalarda kontrollere göre aleksitimi ve anksiyete açısından fark saptamazken depresif belirtiler açısından anlamlı derecede yükseklik saptamışlar. Farklı olarak yine ülkemizde yapılan bir araştırma AA'lı hastalarda kontrollere göre depresyon ve anksiyete düzeyinde fark saptamazken, aleksitimi açısından anlamlı fark saptamışlardır. Aynı çalışmada aleksitimi ile hastaların yaşı, cinsiyeti, hastalık tipi/şiddeti ve hastalık süresi ile ilişki saptanmadığı bildirmişlerdir (Yazıcı ve ark. 2006). 
Araştırmamızda anksiyete, depresyon, aleksitimiden oluşan psikiyatrik belirtiler ile hastalık şiddeti arasında anlamlı bir ilişki saptamadık. Benzer şekilde ülkemizde yapılan çalışmalarda da depresyon ve/veya anksiyete düzeyi ile hastalık şiddeti arasında ilişki saptanmamış (Arı ve ark. 2011, Çelik ve ark. 2010, Güleç ve ark. 2002). Farklı olarak bazı çalışmalarda depresyon ve anksiyete düzeyi ile hastalığın şiddeti arasında anlamlı sonuçlar bildirilmiş (Mulinari-Brenner 2018, Baghestani 2015). Bu farklılığın nedeni çalışmamızdaki hastaların hastalık şiddetinin S1 ve S2 grubunda olması şiddetli formları içermemesinden dolayı olabilir.

Literatürdeki çalışmalarda (Mulinari-Brenner 2018, Ghajarzadeh ve ark. 2011, Çelik ve ark. 2010) olduğu gibi, çalışmamızda bayan hastaların depresyon bulguları erkek hastalara göre anlamlı olarak yüksek saptandı. Bu sonuç kadınların saç dökülmesinin etkilediği dış görünümlerini daha fazla önemsediklerini göstermektedir. AA'lı hastalarda psikiyatrik belirtiler ile hastalık süresi ve hasta yaşı arasında ilişki saptamadık. (Baghestani ve ark. 2015) depresyon ve anksiyete düzeyi ile hasta yaşı ve hastalık süresi arasında ilişki saptamadıklarını bildirmişlerdir.

Çalışmamızın bazı kısıtlılıkları mevcuttur; ilki çalışma grubumuzun göreceli olarak sayıca azlığı, ikincisi AA'lı hastaların tümünün hastalık şiddetinin hafif-orta derecede olmasıydı.

Psikiyatrik bozuklukların veya hastalıkların AA' dfarka tetikleyici faktör olabileceği gibi, hastalığın kendisinin de psikiyatrik problemlere neden olabilir veya mevcut psikiyatrik problemin şiddetlenmesine yol açabilir. AA kişinin diş görünümünde bozukluk oluşturduğu ve tekrarlama eğiliminde olduğundan psikososyal durumu, kişisel ilişkileri ve günlük aktiviteleri olumsuz yönde etkilenmektedir. Bu durum hastalığın prognozunu da etkilemektedir, bu yüzden hastalığı sadece dermatolojik yönden ele alınmamalı aynı zamanda psikiyatrik açıdan da değerlendirilmelidir. Literatürde depresyon tedavisinden 3-6 ay sonra spesifik tedavi verilmeden iyileşen AA hastaları bildirilmektedir (Şahin ve ark. 2018).

Sonuç olarak; çalışmamızda AA'lı hastalarda depresyon, anksiyete düzeyleri kontrolden anlamlı derecede yüksek olarak saptandı ve aleksitimi seviyelerinde ise anlamlı bir fark yoktu. Bu veriler 1şığında, AA hastalarında başarılı bir tedavi için psikiyatrik değerlendirmenin gerekli olduğunu düşünmekteyiz. Psikiyatrik hasarın şiddetini değerlendirmek için kullanılan psikometrik testler bize yol gösterici olacaktır. Gelecekte uygulanacak daha büyük ve kapsamlı psikometrik ölçümler sonucu yapılacak tanı koydurucu psikiyatrik değerlendirmeleri de içeren çalışmalarla, literatürdeki çelişkili sonuçların önüne geçileceğini düşünmekteyiz.

\section{References}

Arı, B. Çenesizoglu, E. Denli, Y. (2011). Alopesi areata hastalarında psikiyatrik belirtiler. Turkderm. 45(4), 203-205.

Aydoğan, Ü. Mutlu, S. Akbulut, H. Taş, G. Aydoğdu, A. ve Sağlam, K. (2012). Hipertansiyon hastalarında anksiyete bozukluğu. Konuralp Tip Dergisi. 4(2), 1-5.

Bagby, R. M. Parker, JDA. Taylor, GJ. (1994). The twenty item Toronto Alexithymia Scale I-II. Item selection and cross validation of the factor structure and Convergent, Discriminant, and Concurrent Validity. J Psychosom Res. 38(1), 23-40.

Baghestani, S. Zare, S. Seddigh, S.H. (2015). Severity of depression and anxiety in patients with alopecia areata in Bandar Abbas, Iran. Dermatol Reports. 7(3), 6063.

Beck, AT. Ward, CH. Mendelson, M. et al. (1961). An inventory for measuring depression. Arch Gen Psychiatry; 4(6), 561-571.

Beck, AT. Epstein, N. Brown, G. et al. (1988). An inventory for measuring clinical anxiety: Psychometric properties. J Consult Clin Psychol. 56(6), 893-897.

Colon, E. A. Popkin, M.K. Callies, A.L. et al. (1991). Lifetime prevalence of psychiatric disorders in patients with alopecia areata. Comprehensive Psychiatry. 32(3), 245-251.

Cordan Yazıcı, A. Başterzi, A. Tot Acar, Ş. Üstünsoy, D. İkizoğlu, G. Demirseren, D. Kanık, A. (2006). Alopesi areata ve aleksitimi. Türk Psikiyatri Derg. 17(2), 101-106. 
Çalıkoğlu, E. ve Alpay, F. B. (2000). Pruri universalis, alopecia areata, psoriasis vulgaris ve kronik ürtikerde Beck depresyon, Durumluluk ve süreklilik kaygı envanterlerinin değerlendirilmesi. $T$ Klin Dermatol. 10, 229-232.

Çelik, T. Akman, A. Karaman, T. Başaran, E. Yılmaz, E. (2010). Alopesi areata ve akne vulgarisin ruhsal durum üzerine etkileri. Turk J Dermatol. 4, 4-8.

Dizen-Namdar, N. ve Arıkan, İ. (2019). Alopesi Areata ve Vitiligo Hastalarında D Vitamini Düzeyinin Yaşam Kalitesi ile İlişkisi. Turk J Osteoporos. 25(1), 35-39.

Doruk, A. Tunca, M. Koç, E. Erdem, M. ve Uzun, Ö. (2009). Psöriyazis ve Alopesi Areatalı Erkek Olgularda Aleksitimi, Öfke-Öfke İfade Tarzı ve Mizaç Karakter Özellikleri. Turkiye Klinikleri J Med Sci. 29(6), 1503-1509.

Ghajarzadeh, M. Ghiasi, M. ve Kheirkhah, S. (2011). Depression and quality of life in Iranian patients with Alopecia Areata. Iran J Dermatol. 14(58), 140-143.

Ghanizadeh, A. Ayoobzadehshirazi, A. (2014). A review of psychiatric disorders comorbidities in patients with alopecia areata. Int J Trichology. 6, 2-4.

Güleç, A. T. Taşkıntuna, N. Duru, Ç. ve ark. (2002). Alopsi areatada psikolojik faktörlerin rolü ve hastalığın yaşam kalitesi üzerine etkisi. Türkderm. 36(3), 178-181.

Güleç, H. Köse, S. Güleç, M.Y. et al. (2009). Reliability and Factorial Validity of the Turkish Version of the 20-Item Toronto Alexithymia Scale (TAS-20). Klinik Psikofarmakoloji Bülteni, 19(3), 214220.

Güleç, H. Yenel, A. (2010). 20 Maddelik Toronto Aleksitimi Ölçeği Türkçe Uyarlamasının Kesme Noktalarına Göre Psikometrik Özellikleri. Klin Psikiyatr Derg. 13(3), 108-112.

Hisli, N. (1988). Beck Depresyon Ölçeği’nin bir Türk örnekleminde geçerlilik ve güvenilirliği. Psikoloji Dergisi. 4(22), 118-122.

Mulinari-Brenner, F. (2018). Psychosomatic aspects of alopecia areata. Clin Dermatol. 36(6), 709713.

Olsen, E. Hordinsky, M. McDonald-Hull, S. Price, V. Roberts, J. Shapiro, J. Stenn, K. (2004). Alopecia areata investigational assessment guidelines-Part II. J Am Acad Dermatol. 51(3), 440447.

Picardi, A. Pasquini, P. Cattaruzza, MS ve ark. (2003). Psychosomatic factors in first-onset alopecia areata. Psychosomatics, 44(5), 74-381.

Poot, F. (2004). Psychological consequences of chronic hair diseases. Rev Med Brux, 25, 286-288.

Rajoo, Y. Wong, J. Cooper, G. et al. (2019). The relationship between physical activity levels and symptoms of depression, anxiety and stress in individuals with alopecia areata. BMC Psychol. $7(1), 48$

Sifneos, PE. (1988). Alexithymia and its relationship to hemispheric specialization, affect, and creativity. Psychiatr Clin North Am. 11(3), 287-292.

Şahin, G. Ö. Akyol, M. Kuğu, N. ve Özçelik, S. (2018). Alopesi Areata Olgularında Depresyon. C. $\ddot{U}$. Tıp Fakültesi Dergisi. 30(2-3-4), 68-71. 
Şaşıoğlu, M. Gülol, Ç. Tosun, A. (2013). Aleksitimi Kavramı Psikiyatride Güncel Yaklaşımlar. Current Approaches in Psychiatry. 5(4), 507-527.

Taycan, O. Özdemir, A. Erdoğan, S. (2017). Alexithymia and Somatization in Depressed Patients: The Role of the Type of Somatic Symptom Attribution. Arch Neuropsychiatry. 54(2), 99-104.

Ulusoy, M. Şahin, N. H. Erkmen, H. (1998). Turkish version of the Beck Anxiety Inventory: Psychometric properties. J Cognitive Psychother. 12(2), 163-172.

Yaylı, S. Tiryaki, A. Doğan, S. İskender, B. ve Bahadır, S. (2012). Alopesi Areatada stresin rolü ve hastaların yaşam kalitesinin androgenetik alopesi ve sağlıkl kontrollerle karşılaştırılması. Türkderm. 46(3), 134-137. 